\title{
RACK AND PINION STEERING SYSTEM DESIGN FOR A PASSENGER CAR
}

\section{Andrei-Constantin SOFIAN, Bogdan Manolin JURCHIS,, Mădălin Florin POPA}

Technical University of Cluj-Napoca, Romania e-mail: madalin.popa@live.com

\begin{abstract}
The steering system plays a crucial role in the stability of the automobile, especially in the safety of the passengers and pedestrians. The aim of this work is to design a rack and pinion steering system that could equip a passenger car. In this process, many parameters are considered for the correct and effective directional response behavior of the vehicle. $2 \mathrm{D}$ models were sketched to validate the kinematic algorithm calculus used to optimize and refine the dimensions of the components of the steering system. After a satisfactory Ackermann percentage was achieved, steering system is designed and analysed in one of the most used CAD and CAE software in automotive, CATIA.
\end{abstract}

KEYWORDS: rack and pinion, steering kinematics, Ackerman geometry, optimization, CAD, CAE, turning angle, turn centre

\section{Introduction}

Devised by the English physician Erasmus Darwin in 1758 , designed by the German carriage builder George Lankensperger in 1817, and patented by the Anglo-German bookseller Rudolph Ackermann in 1818, Ackermann geometry proposed a new method of steering of horse-drawn carriages, whose stability in turning was very low at that time. This new method aims that the two front wheels should turn about a centre that lies on the extended line of the back axle of the carriage. Respecting this principle means that all four wheels will have concentric paths. These concentric paths of the wheels come with some important advantages: the front wheels both run tangential to the track, so there is no scuffing anymore of the wheels on the road, but more important, the carriage turns more smoothly and the probability of overturning decreases insignificantly. It is essential to know these facts because the automotive steering system is also designed considering this principle discovered by Darwin and Lankensperger [1].

Throughout this paper many parameters will be encountered, so it is absolute necessary to clarify the terminology.
Table 1. Nomenclature

\begin{tabular}{|c|c|c|}
\hline Parameter & Notation & $\begin{array}{c}\text { Measure } \\
\text { unit }\end{array}$ \\
\hline Wheelbase & $\mathrm{A}$ & {$[\mathrm{mm}]$} \\
\hline Wheel track & $\mathrm{E}$ & {$[\mathrm{mm}]$} \\
\hline Inner tier turning angle & $v_{i}$ & {$\left[{ }^{\circ}\right]$} \\
\hline Outer tier turning angle & $v_{e}$ & {$\left[{ }^{\circ}\right]$} \\
\hline Turning radius & $\mathrm{R}$ & {$[\mathrm{mm}]$} \\
\hline
\end{tabular}

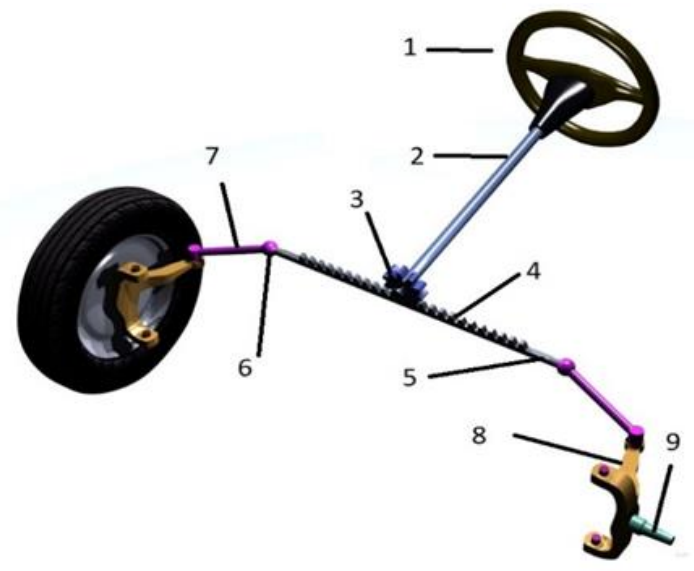

Fig. 1. Steering system components: 1-steering wheel, 2-steering column, 3-pinion, 4-rack, 5transverse bar, 6-rod end, 7-tie rod, 8-steering lever, 9-spindle [2] 


\section{THE ANNALS OF "DUNAREA DE JOS” UNIVERSITY OF GALATI \\ FASCICLE IX. METALLURGY AND MATERIALS SCIENCE \\ $\mathrm{N}^{\circ} .4$ - 2021, ISSN 2668-4748; e-ISSN 2668-4756 \\ Article DOI: https://doi.org/10.35219/mms.2021.4.14}

This paper aims to describe the logical steps that must be considered in designing an effective steering system for a passenger car. A steering system is effective if the paths of the wheels are concentric, in other words, the turn centre is placed on the extended line of the back axle. For achieving such concentric trajectories, the inner wheel must be steered more than the outer wheel. In Figure 2 is presented the ideal turn or Ackermann principle.

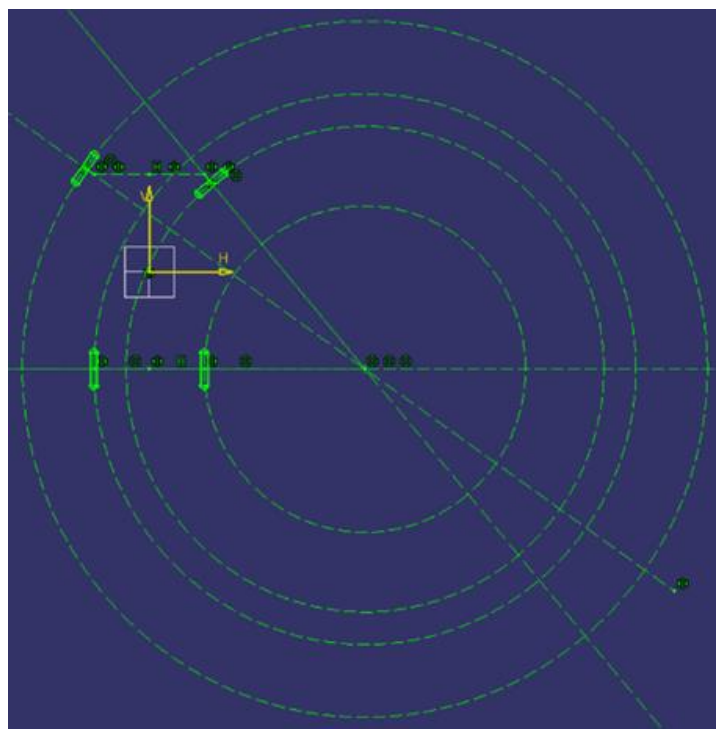

Fig. 2. Ideal 360 turn/ Ackermann turn

It is very important to know that such an ideal turn is a consequence of the steering geometry and steering kinematics [3]. Based on Figure 2, the next equation can be deduced, an equation which defines the ideal dependency between the two turning angles of the front wheels.

Theoretically, the ideal turn is based on a very simple equation. In real life, the trajectories of the wheels depend on such a complex system called steering system, and not only. Plotting this first equation, it will result the next chart.

$$
v_{e}=\operatorname{acot}\left(\frac{\mathrm{E}}{A}+\cot \left(v_{i}\right)\right)
$$

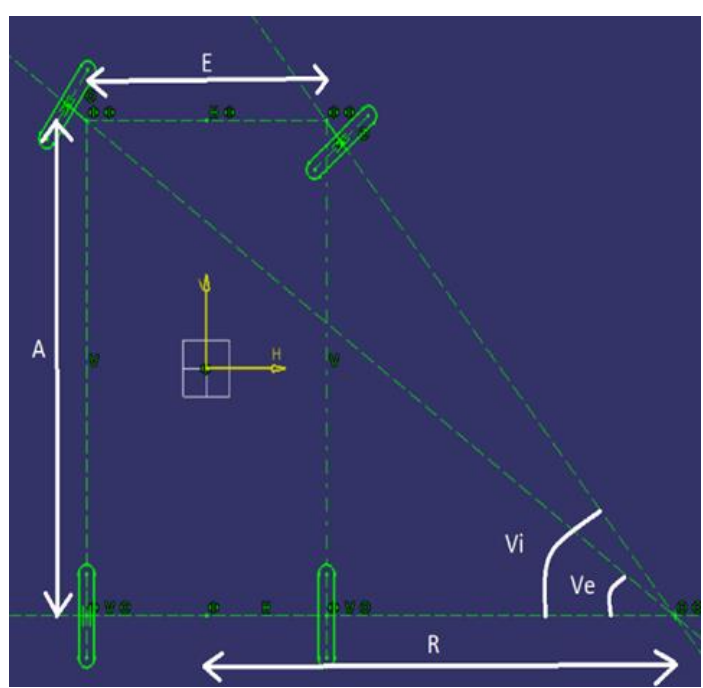

Fig. 3. Ideal turn angles

Ideal dependency between the two turning angles of the front wheels

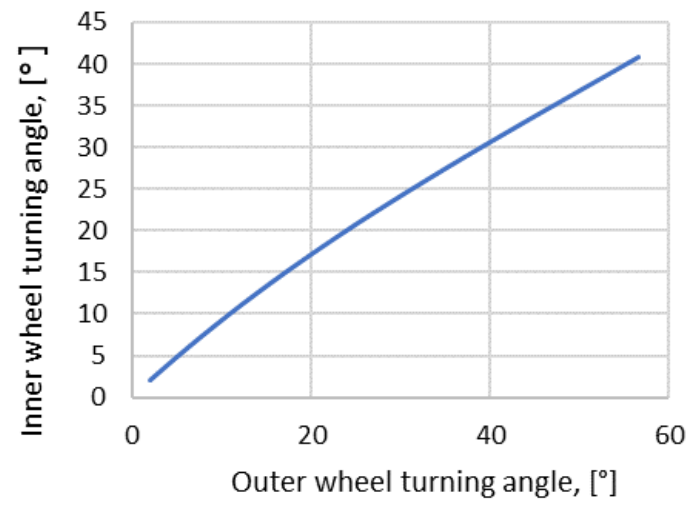

The blue line becomes our objective at this stage and, for achieving such an ideal curve, a kinematic algorithm is needed.

\section{Kinematic algorithm}

Every calculus algorithm has an input and an output.

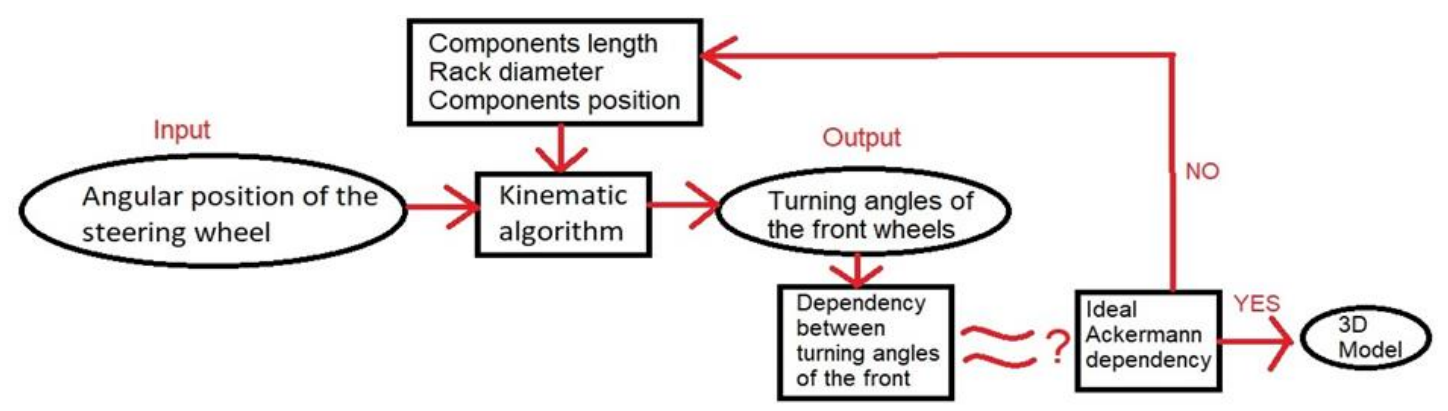

Fig. 4. Kinematic algorithm overview 


\subsection{Ackermann's angles}

The theory proposes that the possibility of achieving Ackermann geometry is greater if the intersection point of the extension of steering arms is placed in the middle of the rear axle [5].

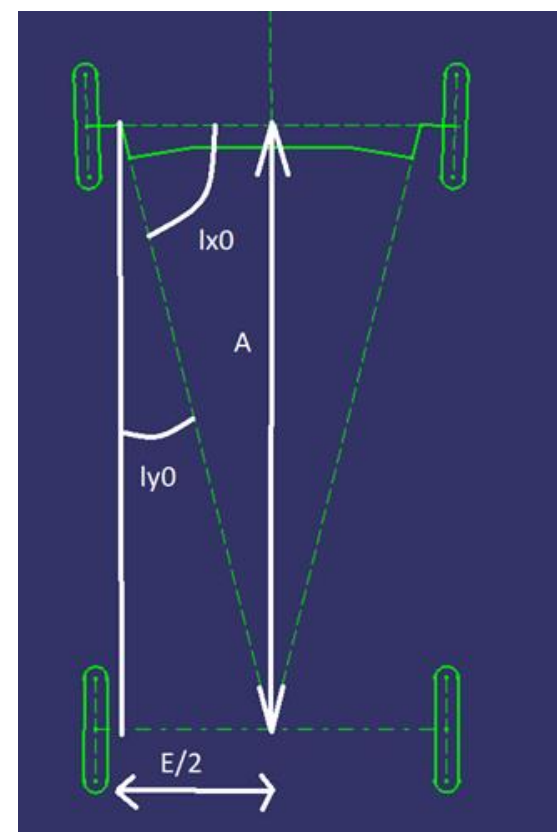

Fig. 5. Ackermann angles

Verry important for the following calculations are the two angles from Figure 5.

$$
l_{\mathrm{y} 0}=\arctan \left(\frac{\frac{E}{2}}{A}\right) ; l_{\mathrm{x} 0}=90^{\circ}-l_{\mathrm{y} 0}
$$

\subsection{Length of the tie rod}

As in the figure 1, in figure 6 we see the following components: 1-steering arm, b-tie rod, ttransverse bar, B and C- rod ends and A- steering axis.

$$
\begin{gathered}
x_{A}=\frac{E}{2} ; y_{A}=0 ; x_{C}=\frac{t}{2} \\
x_{\mathrm{B}}=x_{A}-l \sin \left(l_{y 0}\right) \\
b=\sqrt{\left(x_{C}-x_{B}\right)^{2}+\left(y_{C}-y_{B}\right)^{2}}
\end{gathered}
$$

For finding out the length of the tie rod, the first two unknown parameters, $\mathrm{t}$ and $y_{C}$, have been introduced. Till now, we analysed the steering linkage only in neutral position, in other words, the car is not turning. The car is steering only if the rack is moving in the rack and pinion box. Now, the third unknown parameter is introduced.

$$
\mathrm{x}=\pi \cdot d_{p} \cdot \frac{\varphi_{v}}{360^{0}}
$$

In equation 6: $\mathrm{x}$ - transverse bar displacement in $\mathrm{x}$ direction, the only direction the rack is moved by the driver via steering wheel; $d_{p}$ - pinion diameter, the third unknown parameter, and $\varphi_{v}$ - our input parameter, the angular position of the steering wheel. For passenger cars, the steering wheel makes 1.5 turns. This means that our input vector is $\left[-540^{\circ}\right.$, $+540^{\circ}$ ].

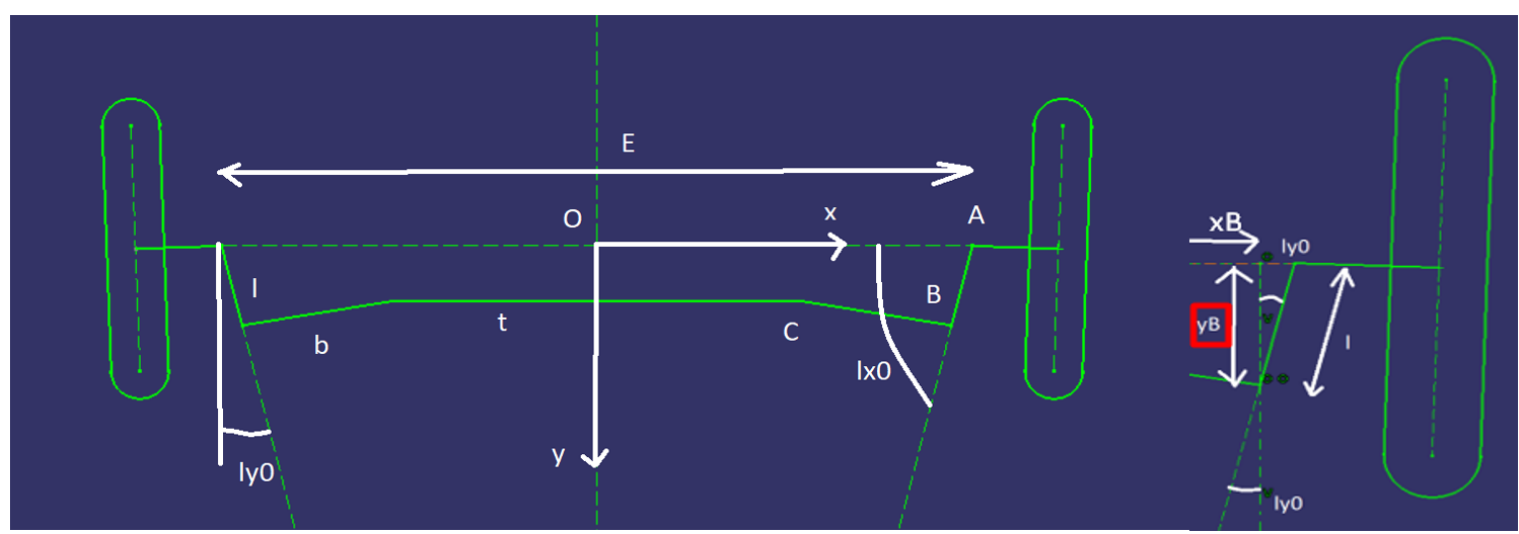

Fig. 6. Length of the tie rod 


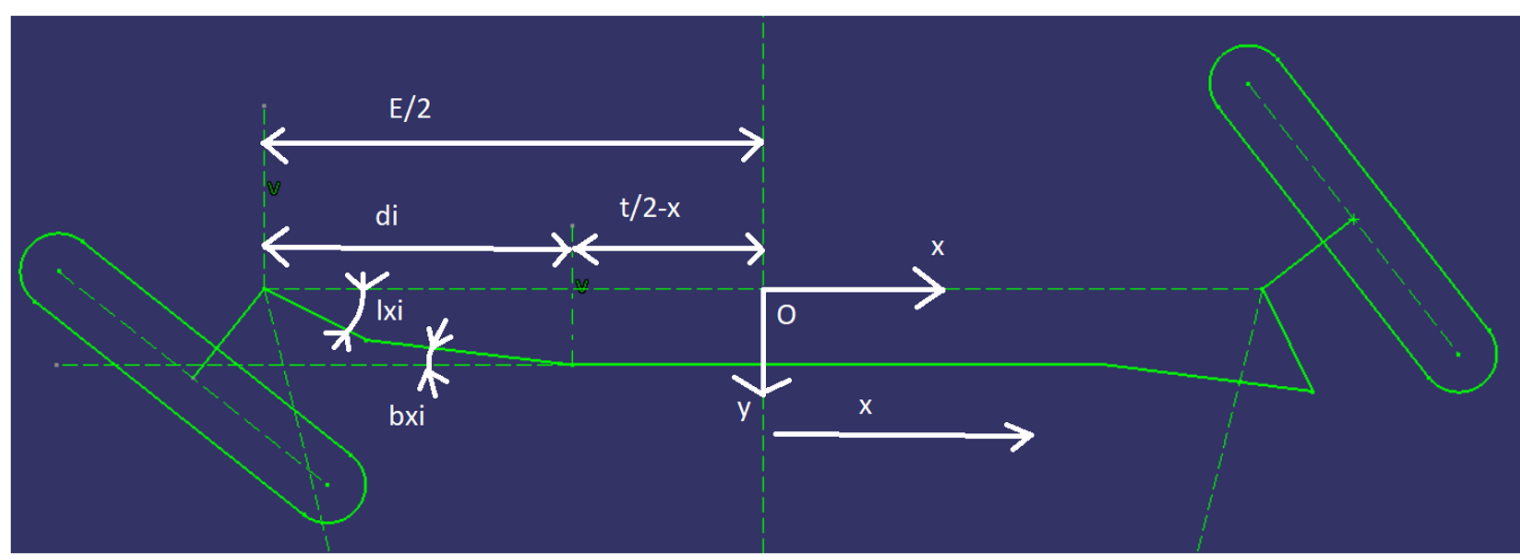

Fig. 7. Top view of the steering linkage for finding the turn angle of the inner wheel

\subsection{Turn angle of the inner wheel}

$$
\begin{aligned}
& d_{\mathrm{i}}=\frac{E}{2}-\frac{t}{2}+x \\
& b \cdot \cos \left(b_{x i}\right)=d_{i}-l \cdot \cos \left(l_{x i}\right) \\
& b \cdot \sin \left(b_{x i}\right)=y_{c}-l \cdot \sin \left(l_{x i}\right) \\
& b^{2}=d_{i}^{2}+y_{c}^{2}+l^{2} \\
& -2 \cdot d_{i} \cdot l \cdot \cos \left(l_{x i}\right) \\
& -2 \cdot y_{C} \cdot l \cdot \sin \left(l_{x i}\right) \\
& 2 \cdot d_{i} \cdot l \cdot \cos \left(l_{x i}\right) \\
& +2 \cdot y_{c} \cdot l \cdot \sin \left(l_{x i}\right) \\
& +b^{2}-d_{i}^{2}-y_{c}{ }^{2}-l^{2}=0 \\
& P \cdot \cos \left(l_{x i}\right)+Q \cdot \sin \left(l_{x i}\right)+R=0 \\
& P=2 \cdot d_{i} \cdot l ; Q=2 \cdot y_{C} \cdot l ; \\
& R=b^{2}-d_{i}^{2}-y_{c}{ }^{2}-l^{2} \\
& \sin \left(l_{x i}\right)=\frac{2 \cdot \tan \left(\frac{l_{x i}}{2}\right)}{1+\tan \left(\frac{l_{x i}}{2}\right)^{2}} \\
& \cos \left(l_{x i}\right)=\frac{1-\tan \left(\frac{l_{x i}}{2}\right)}{1+\tan \left(\frac{l_{x i}}{2}\right)^{2}} \\
& \sin \left(l_{x i}\right)=\frac{2 \cdot z}{1+z^{2}}
\end{aligned}
$$

$$
\begin{gathered}
\cos \left(I_{x i}\right)=\frac{1-z}{1+z^{2}} \\
P \cdot \frac{1-z}{1+z^{2}}+Q \cdot \frac{2 \cdot z}{1+z^{2}}+R=0 \\
(R-P) z^{2}+2 Q z+P+R=0 \\
a=(R-P) ; b=2 Q ; c=P+R \\
\Delta=b^{2}-4 a c \\
z=\frac{-b-\sqrt{\Delta}}{2 a} \\
z=\tan \left(\frac{l_{x i}}{2}\right) \\
l_{x i}=2 \cdot \arctan (z) \\
\beta_{i}=l_{x 0}-l_{x i}
\end{gathered}
$$

In these equations we used for the first time "l", so we introduced our last unknown parameter. " $\beta_{i}$ " is the angular variation of the inner wheel. There still is a toe angle, the angle that each tire makes with the longitudinal plane of the vehicle. For most passenger cars, the front tires are not only for steering, but also for traction. Because of this, even if the angular position of the steering wheel is " 0 ", the front tires will be very little steered, that angle being called toeout angle. Therefore, also this small angle must be considered for the final value [4].

$$
v_{i}=\beta_{i}-\gamma_{0}
$$




\subsection{Turn angle of the outer wheel}

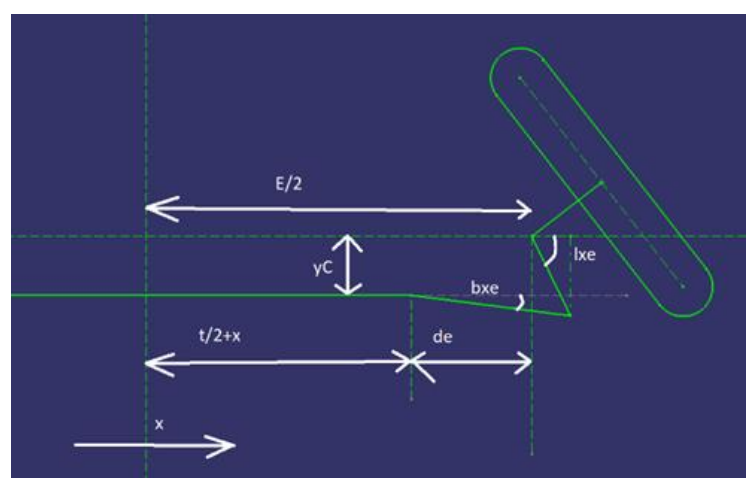

Fig. 8. Top view of write half steering linkage

The calculation method is almost identical with only a few differences.

$$
\begin{gathered}
d_{e}=\frac{E}{2}-\frac{t}{2}-x \\
b \cdot \cos \left(b_{x e}\right)=d_{e}+l \cdot \cos \left(l_{x e}\right) \\
b \cdot \sin \left(b_{x e}\right)=l \cdot \sin \left(l_{x e}\right)-y_{c} \\
b^{2}=d_{e}^{2}+y_{c}{ }^{2}+l^{2} \\
2 \cdot d_{e} \cdot l \cdot \cos \left(l_{x e}\right) \\
-2 \cdot y_{c} \cdot l \cdot \sin \left(l_{x e}\right) \\
2 \cdot \mathrm{d}_{e} \cdot l \cdot \cos \left(l_{x e}\right) \\
-2 \cdot y_{c} \cdot l \cdot \sin \left(l_{x e}\right) \\
-b^{2}+d_{e}^{2}+y_{c}{ }^{2}+l^{2}=0 \\
P \cdot \cos \left(l_{x e}\right)+Q \cdot \sin \left(l_{x e}\right)+\mathrm{R}=0 \\
P=2 \cdot d_{e} \cdot l ; Q=-2 \cdot y_{c} \cdot l \\
\mathrm{R}=-b^{2}+d_{e}^{2}+y_{c}^{2}+l^{2}
\end{gathered}
$$

From this point, equations (14)-(24) are the same, but this time we are trying to find the outer wheel turning angle, " $l_{x e} "$, not " $l_{x i} "$. As we found out " $l_{x e}$ ", based on Figure 9 we can deduce the angular variation of the outer wheel.

$$
\begin{gathered}
\beta_{e}=\left(180-l_{x e}\right)-l_{x 0} \\
v_{e}=\beta_{e}+\gamma_{0}
\end{gathered}
$$

In equation (52), as in (26), the $\gamma_{0}$ is a toe out angle.
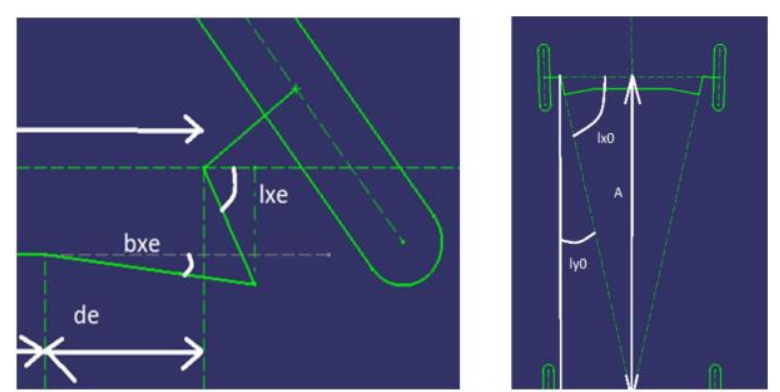

Fig. 9. Turning angle of the write wheel

\section{Results}

We see that there is no chance for an ideal rack and pinion steering system. Mathematically, it is impossible to obtain a 'blue curve' for every angular position of the steering wheel for a rack-and-pinion steering system. If we cannot obtain a "blue curve" for all steering wheel positions, then we can try to obtain it for large turning angles at least, where the speed of the vehicle is very low, and the car cannot take advantage of the slip angle.

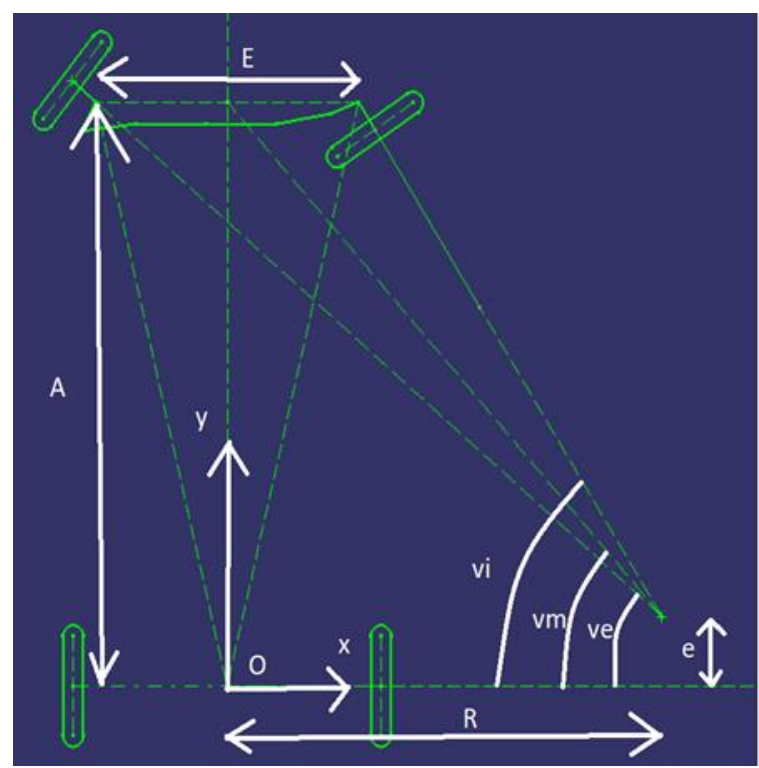

Fig. 10. Ackermann error

$$
\begin{gathered}
R=\frac{E}{2} \cdot \frac{\tan \left(v_{e}\right)+\tan \left(v_{i}\right)}{\tan \left(v_{i}\right)-\tan \left(v_{e}\right)} \\
e=A-\left(R-\frac{E}{2}\right) \tan \left(v_{i}\right)
\end{gathered}
$$

As we can see, the relative error between our results and Ackermann principle is less than 5\% for very tight curves. Moreover, the fact that in the less tight curve domain, the error is very high is normal. 
In this domain, the car is running almost straight with a higher speed, which increases the slip angle. Slip angle will reduce this high error. The values of slip angle are very unpredictable because they are based on many complex aspects regarding vehicle dynamics. In this paper an Ackermann curve in low speeds domain (extreme angular steering wheel positions) is desired to be obtained.

$$
\varepsilon=\frac{\left|v_{\text {ideal }}-v_{\text {real }}\right|}{v_{\text {ideal }}} \cdot 100
$$

Dependency between the two turning angles of the front wheels
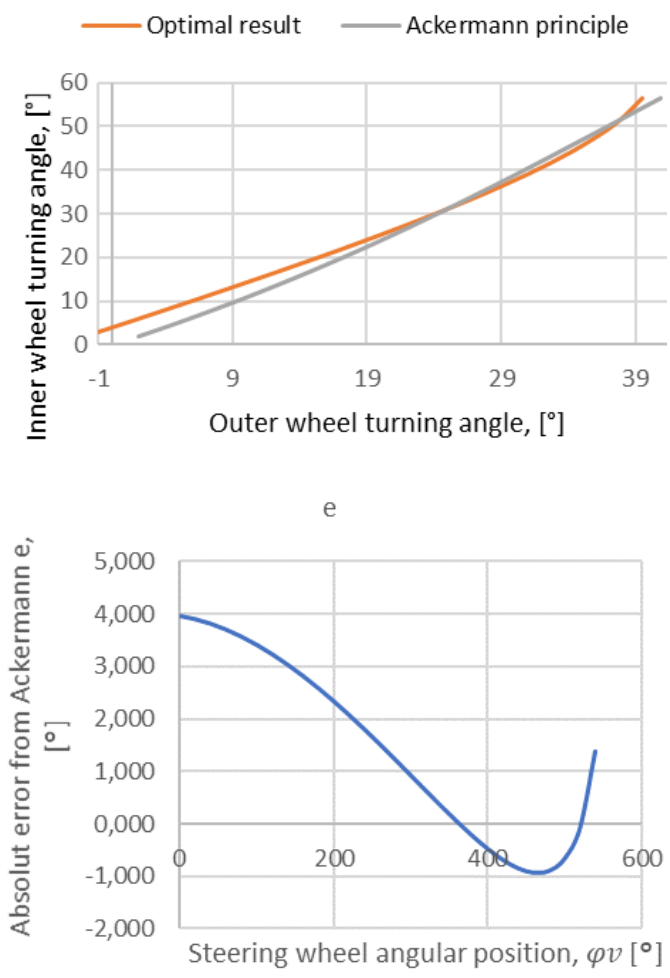

Relative error from Ackermann

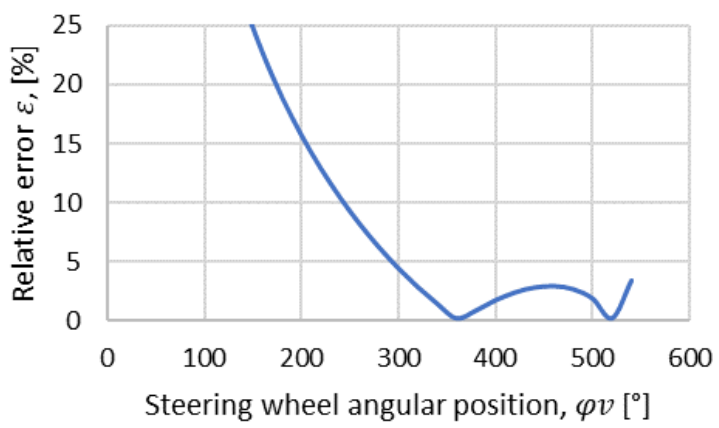

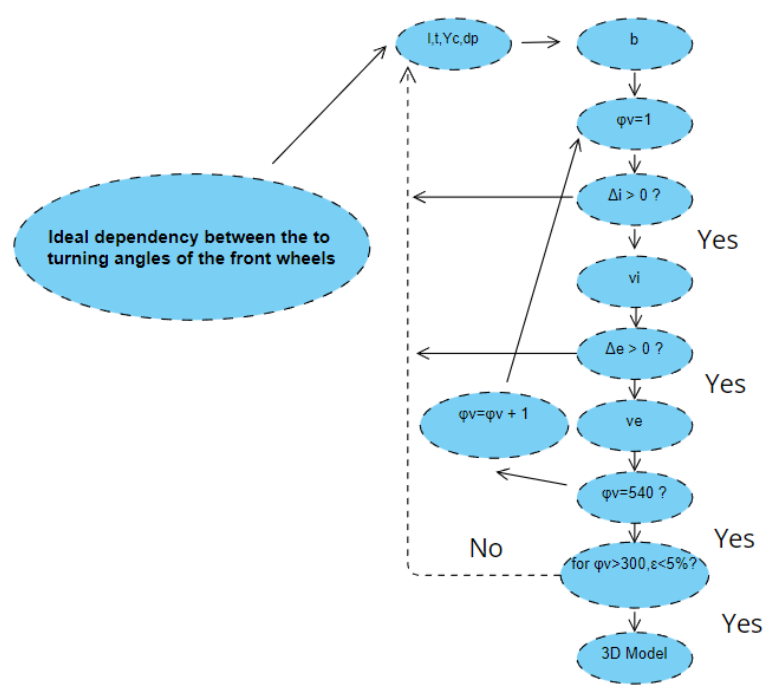

Fig. 11. Kinematic algorithm

After a lot of iterations these are the winning values which define the steering linkage geometry:

Table 2. Winning values

\begin{tabular}{|c|c|c|}
\hline Notation & Measure unit & Value \\
\hline$l$ & {$[\mathrm{~mm}]$} & 150 \\
\hline$t$ & {$[\mathrm{~mm}]$} & 700 \\
\hline$y_{C}$ & {$[\mathrm{~mm}]$} & 100 \\
\hline$d_{p}$ & {$[\mathrm{~mm}]$} & 22 \\
\hline
\end{tabular}

The only known from the beginning parameters were:

Table 3. Known dimensions

\begin{tabular}{|c|c|c|c|}
\hline Parameter & Notation & $\begin{array}{c}\text { Measure } \\
\text { unit }\end{array}$ & Value \\
\hline Wheelbase & A & {$[\mathrm{mm}]$} & 2650 \\
\hline Wheel track & E & {$[\mathrm{mm}]$} & 1530 \\
\hline
\end{tabular}

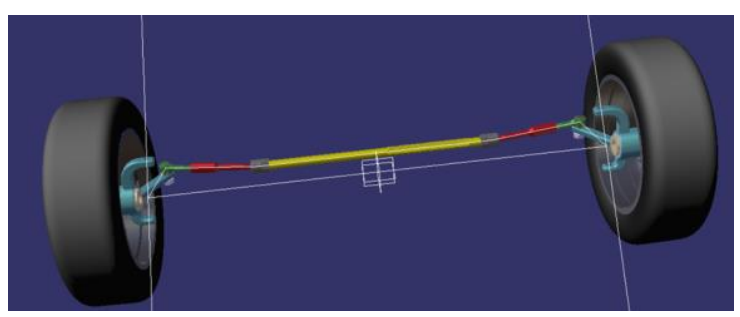

Fig. 12. Steering linkage $C A D$ 


\section{THE ANNALS OF "DUNAREA DE JOS" UNIVERSITY OF GALATI \\ FASCICLE IX. METALLURGY AND MATERIALS SCIENCE \\ No. 4 - 2021, ISSN 2668-4748; e-ISSN 2668-4756 \\ Article DOI: https://doi.org/10.35219/mms.2021.4.14}

4. CAD and CAE

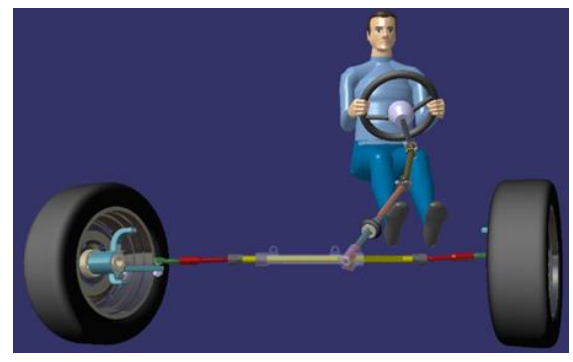

Fig. 13. Steering system $C A D$

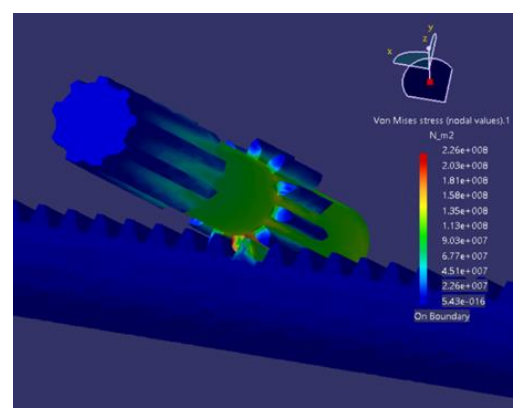

Fig. 14. Finite Element Analyse for rack and pinion

Table 4. Materials

\begin{tabular}{|c|c|}
\hline Component & Material \\
\hline Rack and Pinion & 42CrMo4 \\
\hline Tie rod & High strength steel \\
\hline Rod end & PH13-8Mo \\
\hline Steering knuckle & Al 7057-T6 \\
\hline Steering column & Carbon fiber \\
\hline
\end{tabular}

\section{Conclusions}

This paper presents a possible approach to the design and optimization of a such a complex system as a steering system. The project started with a very solid objective, an algorithm calculus has been created based on 2D sketches, the dimensions of the steering linkage were continuously changed based on the algorithm. If $2 \mathrm{D}$ model helped the kinematic improvement of the system, later, a CAD model has been created for running kinematic simulations and finite element analyses. It is also well to know that even if Ackermann is the most used name in steering system design, there were another 2 men, Darwin and Lnakensperger, who invented a steering linkage geometry used in horse-drawn carriages for improving the stability, a geometry which is also used today in our cars steering system. We also saw that it is very hard to keep all four wheels on concentric paths with a mechanical steering system. Also, to be noticed that a toe out angle is often used for a better steerability.

\section{References}

[1]. King-Hele D., Erasmus Darwin's Improved Design for Steering Carriages-And Cars, Notes and Records of the Royal Society of London, 56 (1), p. 41-62. http://www.jstor.org/stable/532121, 2002.

[2]. ***, https://axleaddict.com/.

[3]. Harrer M., Pfeffer P., Steering Handbook, Springer, 2017.

[4]. Untaru M., Cîmpian V., Ionescu E., Seitz N., Soare I., Automobile, București, 1975.

[5]. Frățilă G., Calculul și construcția automobilelor, București. 